Beograd

\title{
SUR L'EMPLOI FACULTATIF DE L'ARTICLE DÉEINI EN FRANÇAIS
}

Il y a un domaine où la syntaxe descriptive du français moderne est bien lacunaire. Il s'agit notamment de l'emploi facultatif de l'article défini. Inutile de dire de quelle importance cette question peut être, surtout pour les étrangers.

On sait que dans beaucoup d'expressions le sens varie selon la présence ou l'absence de l'article (cf. contre nature - contre la nature, faire loi - faire la loi, rendre justice - rendre la justice). Pourtant dans une quantité de cas cette différence sémantique est neutralisée, ou presque complètement effacée. Par exemple dans ces locutions verbales: aimer (la) besogne faite; amener (le) pavillon; avoir (du) regret de; avoir (de la) peine à + inf.; avoir (le) coeur au métier; battre (le) pavillon; courir (le) hasard; courir (le) risque; faire (la) queue; perdre (l')haleine; trouver (le) moyen; venir en (l') esprit. Ou bien dans d'autres tournures comme celles-ci: à (la) portée; $a$ (la) première vue; à (la) bonne sorte; dès (le) potron minet; os à (la) moelle; par dessus (la) jambe, etc.

Il faut cependant remarquer que certaines locutions avec article sont considérées comme fautives, ou bien appartenant à "un style un peu gros. ${ }^{1}$ Telle serait, par exemple, la locution avoir l'envie de +inf. En partant de cette opinion, nous avons analysé l'emploi alternatif de cette tournure dans le roman Aurélien d'Aragon (ed. Gallimard, 1944). Les résultats obtenus donnent l'image qui suit.

\section{a) Les exemples où l'article fait défaut}

1. Brusquement Mary sentit la jalousie, la vraie. Elle eut envie de crier, et se mordit les lèvres (65).

2. J'ai eu quinze jours de mise à pied l'autre mois... Tu parles si j'ai envie de recommencer (71).

3. Il ne faut pas les voir dans le grand jour. A moins qu'on ne soit dans une de ces séries où on a envie de chialer (74).

4. Une petite provinciale qui a envie de voir Paris (109).

5. Je n'ai pas envie d'aller au théâtre sans vous (140).

6. S'il avait envie pourtant de l'entourer de ses bras, de la serrer contre lui (143).

Cf. G. et R. Le Bidois, Syntaxe du français moderne I, 2-ème édition, Paris, Picard, 1971, p. 46 $\S 80$.

F. Brunot, La Pensée et la Langue, Paris, Masson, 1936, p. 163, note (1). 
7. Il avait envie d'apporter des corrections à cette femme (206).

8. Il sait bien ce qu'il fait et que les gens n'ont pas envie de se coucher après le théâtre, que Monmartre commence tard (246).

9. Aurélien a peur et envie d'écouter ce que les gens vont en dire (248).

10. Il eut envie de dire: Je sais. Il se retint. Il dit: "Mon Dieu!... mais... asseyez-vous... (269).

11. [...] parce qu'il avait envie de se dire qu'il appartenait à cette société-là au moins $[\ldots .].(199)$.

12. Decoeur se mordit un peu les lèvres. Pas qu'il ê̂t envie de rire (233).

13. Elle avait envie de faire l'amour (335).

14. J'ai envie de te gifler (342).

15. J'ai envie de parler (368).

16. Bérénice n'avait aucune envie de voir les amis de Paul (382).

17. Elle $n$ 'avait pas une telle envie de voir Archibald et Molly (384).

18. Vous m'excuserez, Molly, j'ai envie d'aller me promener (390).

19. Aucune autre femme n'a compté pour moi dans la vie ...aucune autre... quand je pense aux autres, $j$ 'ai envie de rire (442).

20. Une de ces nuits de Paris où on n'a pas envie d'aller se coucher (446).

b) Les exemples où l'article est employé

21. Mais pour une fois, il avait l'envie de se laisser un peu faire violence (45).

22. Ce n'est pas que Bérénice ait l'envie de faire la conversation, mais elle sent qu'il y a quelque chose qui ne va pas entre ses cousins (56).

23. Mme de Perseval en eut presque l'envie de pleurer (63).

24. Il se sentait [...] de l'envie qu'il avait eue d'étrangler cette femme (118).

25. Il n'avait pas l'envie de divorcer, du moins encore (378).

26. Il ravala l'envie qu'il avait de pleurer (403).

27. Elle n'avait plus l'envie d'aller chez Valmondois (422).

28. Quand Edmond l'a enveloppé dans son manteau, il a eu un moment l'envie de dire à sa femme: "Restons... tant pis pour la fête!" (423).

29. Au fond, Aurélien avait terriblement l'envie de s'étendre (492).

30. [...] elle avait encore l'envie de discuter (498).

Des exemples relevés s'imposent ces deux conclusions:

$1^{\circ}$ Au point de vue de la répartition, c'est la locution sans article qui prévaut considérablement.

$2^{\circ} \mathrm{Au}$ point de vue sémantique on peut dire qu'il n'y a pas de différence entre les deux formes de la locution en question.

Toutefois, il faut remarquer que l'exemple sous le numéro 26 offre la possibilité de comprendre l'article dans le sens très proche du démonstratif cette, ce qui veut dire que le substantif même y garde sa valeur authentique. Cela n'empêche pas de con- 
clure qu'Aragon s'est servi largement, ici aussi, de la tournure qui appartiendrait plutôt à "la langue de la conversation".2

Etant donné qu'en ancien français l'emploi facultatif de l'article défini était, d'une façon générale, plus fréquent qu'en français moderne, il est curieux de voir à cette occasion les résultats d'une analyse de la tournure adverbiale a tere/a la tere dans la Chanson de Roland. ${ }^{3}$

a) La locution a tere

1. Quant le dut prendre, si li cait a tere (333). (quand il eut à le prendre, il lui tomba à terre).

2. Getet le a tere, sil receit Blancandrin (464). (il le jette à terre; Blancandrin le reçoit).

3. Franceis descendent, a tere se sunt mis (1136). (Les Français descendent de cheval, ils se sont mis contre terre (1136).

4. Guardet a tere, veit gesir le glutun (1230). (Il regarde à terre, il voit gésir le traîte).

5. Voeillet o nun, $a$ tere chet pasmet (2220). (bon gré mal gré, il tombe évanoui à terre).

6. Li quens Rollant veit l'arcevesque a tere (2246). (Le comte Roland voit l'archevêque à terre).

7. Culchet sei a tere, si priet Damnedeu (2449). (il se couche sur le sol, il prie le Seigneur Dieu).

8. Culchet sei a tere, sin a Deu graciet (2480). (Il se couche sur le sol et remercie Dieu).

9. Entre lur piez a tere le tresturnent (2587). (le jettent à terre à leurs pieds).

10. Guardet a tere, veit gesir sun nevuld (2894). (Il regarde à terre, il voit son neveu étendu).

11. Cheent li rei, a tere se turnerent (3574). (les rois tombent à terre, ils se retournent).

12. Les alves turnent, les seles cheent a tere (3881). (les deux bosses tournent, les selles tombent à terre).

2 En parlant de l'emploi de l'article des et de la négation pas Paul Imbs conclut: "Ce sont encore des emplois venus directement de la langue de la conversation et maintenant adoptés par une certaine littérature." P. Imbs, Notes sur la syntaxe du français contemporain d'après Aurélien de Louis Aragon, en Le Francais Moderne XVI (1948), $\mathrm{n}^{\circ} 2$, p. 102.

3 Nous avons utilisé la 2-ème édition de Gérard Moignet (Paris, Bordas, 1971). 
13. A tere sunt ambdui li chevaler (3883). (Les deux chevaliers sont à terre).

b) La locution a la tere

14. Josqu'a la tere si chevoel li balient (976). (Ses cheveux flottent, jusqu'à terre).

15. Desent a piet, a la tere se culchet (2013). (il met pied à terre, se couche sur le sol).

16. Trestut le cors a la tere li justet (2020). (Il tombe à terre, étendu de tout son long). ${ }^{4}$

17. Gesir a denz, a la tere sun vis (2025). (qu'il est étendu la face contre terre).

18. Guardet a la tere, il voit son neveu étendu). (Il regarde à terre, il voit son neveu étendu).

19. Just a la tere une piece en abat (3437). (il en abat un morceau à terre).

On voit donc que le rapport entre les deux formes de la locution adverbiale en ancien français ( $a$ tere / a la tere) est bien similaire à celui entre les deux formes de la locution avoir(l')envie de + inf. en français moderne.

Enfin, si modeste qu'elle soit, notre contribution au problème de syntaxe, posé ici, pourra, espérons bien, encourager certains grammairiens à se pencher sur cette question qui exigerait beaucoup d'investigation.

\section{Résumé}

\section{O FAKULTATIVNOJ UPOTREBI ODREĐENOG ČLANA U FRANCUSKOM JEZIKU}

U gramatikama francuskog jezika zanemarena je upotreba fakultativnog određenog člana. Stoga smo u ovom prilogu, posle nekoliko uvodnih primera takve primene u savremenom francuskom jeziku predstavili rezultate iscrpne analize upotrebe jednog glagolskog izraza u Aragonovom romanu Aurélien - avoir (l') envie de + inf. i jednog priloškog izraza u Pesmi o Rolandu - a (la) tere (sa značenjem u savremenom jeziku: à terre, contre terre, sur le sol). Iz date analize se vidi da su oblici bez člana dvostruko češći i u savremenom i u starom jeziku. A što je još važnije, može se reći da u semantičkom pogledu nema razlike između alternativno upotrebljenih formi.

Na kraju, izrazili smo nadu da će se među lingvistima naći takvih istraživača, koji bi datom problemu posvetili dostojnu pažnju kako bi se na osnovu dobijenih rezultata mogla upotpuniti praznina u sintaksi francuskog jezika, što bi prvenstveno za strance bilo od osobite koristi.

4 La traduction de ce vers est de L. Gautier. Elle nous paraît plus adéquate que celle de Moignet (tout son corps se joint à la terre). 